\title{
CURSOS MIGRATÓRIOS E NOVAS CIRCULARIDADES: MIGRANTES DA ÁFRICA OCIDENTAL NO SUL DO BRASIL
}

\author{
Migration courses and new circularities: \\ migrants from West Africa in Southern Brazil
}

\author{
Lucas Cé Sangalli* \\ Maria do Carmo dos Santos Gonçalves**
}

\begin{abstract}
Resumo. Utilizamos os métodos de entrevista narrativa biográfica e reconstrução de caso biográfico para compreender e explicar as experiências de mobilidade de migrantes da África Ocidental no Brasil. O artigo está fundamentado na sociologia do conhecimento, na sociologia de orientação fenomenológica e na sociologia dos processos e figurações. Os resultados indicam a) a limitação de categorias restritivas para a compreensão do fenômeno, como a baseada em eixos geográficos; b) a necessidade de reconstrução dos deslocamentos anteriores e posteriores dos migrantes para explicar seus cursos migratórios; e c) a tradução dos pertencimentos étnico e religioso e de ativos pessoais e familiares em estratégias que impedem reduzir a explicação das motivações para migrar a determinantes estruturais.
\end{abstract}

Palavras-chave: cursos migratórios; pesquisa biográfica; pertencimento; deslocamento; África Ocidental.

\begin{abstract}
We used the methods of biographical narrative interview and biographical case reconstruction to understand and explain the experiences of mobility of migrants from West Africa in Brazil. The article is theoretically grounded on the sociology of knowledge, the phenomenological sociology, and the sociology of figurations and processes. The results point out to a) the limitations of the use of restrictive categories for the understanding of the phenomenon, as the ones based on geographic axes; b) the importance of reconstructing the movements of migrants before and after their migration courses; and c) the transformation of ethnic and religious belongings and of personal and family assets in strategies that avoid reducing the causes for migration to structural constraints.
\end{abstract}

Keywords: migration courses; biographical research; belonging, displacement; West Africa.

Pesquisador no Centro de Métodos em Ciências Sociais - Pesquisa Social Qualitativa (Methodenzentrum Sozialwissenschaften - Qualitative Sozialforschung), Universidade de Göttingen. Göttingen, Alemanha. E-mail: lucas.sangalli@uni-goettingen.de. Orcid: 0000-0002-6209-1767.

** Doutoranda em Ciências Sociais na Pontifícia Universidade Católica do Rio Grande do Sul (PUCRS). Caxiais do Sul - RS, Brasil. E-mail: maria.carmo1975@gmail.com. Orcid: 0000-0002-2740-9856. 
O Brasil tem sido um dos principais destinos de migrantes vindos do continente Africano para a América Latina desde 2010. Os estados do sul do país receberam migrantes oriundos do Senegal e de Gana, mas também de outras regiões da África Ocidental. Visando contribuir para o debate sobre os regimes de mobilidade (Glick Schiller, Salazar, 2012), as trajetórias de deslocamento (Drotbohm, Winters, 2018) e a construção do lugar em um mundo em movimento (Faist, 2013; Lems, 2014), utilizamos a abordagem biográfica (Rosenthal, 2014; Rosenthal, 2017) para compreender e explicar as construções de pertencimento de migrantes em relação a agrupamentos e figurações sociais ao longo do curso migratório da África Ocidental para o Brasil' . Esses cursos expressam uma diversidade de modos de circulação dificilmente enquadrados pelas categorias de mobilidade utilizadas pela literatura específica e pela legislação migratória dos Estados. Essas limitações apareceram nos casos reconstruídos de diversas formas, na medida em que os migrantes vivenciam o componente legal cotidianamente, ora recorrendo ao amparo jurídico, ora transgredindo mecanismos de regulação migratória e de permanência em determinadas regiões, ficando sujeitos a estarem ilegalizados perante a norma dos Estados ${ }^{2}$.

Na primeira parte do artigo, apresentamos as abordagens teóricas do movimento com as quais estabelecemos diálogo para, então, justificarmos a escolha de uma perspectiva biográfica e dos métodos de entrevista narrativa biográfica, reconstrução de caso biográfico e observação participante para compreender e explicar os cursos migratórios de migrantes da África Ocidental no Brasil. Os dois casos são apresentados na seção seguinte do artigo, na qual analisamos as figurações sociais antes, durante e após os cursos migratórios e os pertencimentos dos migrantes e sua relação com as dinâmicas de mobilidade e imobilidade sobre territórios na constituição de espaços. Os resultados indicam a) a limitação de categorias restritivas para a compreensão do fenômeno, como

1 Como sugerido por Brubaker (2004), usamos o termo agrupamento para evitar a) subsumir o pertencimento de migrantes a determinados grupos antes do trabalho empírico e b) fazer uma análise partindo dessa categoria como constituinte básico da sociedade. Optamos, então, pelo estudo do pertencimento porque entendemos que essa noção está orientada pelas vivências cotidianas dos indivíduos em agrupamentos nas figurações sociais. O termo figuração é utilizado para referir as relações assimétricas de poder entre agrupamentos de indivíduos de acordo com Elias $(1991 ; 2008 ; 2018)$. O foco nas experiências dos sujeitos permite acesso à constituição mútua entre indivíduo e sociedade ao mesmo tempo em que evita reificar estruturas sociais (May, 2011). Com isso, é possível compreender como práticas cotidianas respondem a padrões sociais sem desconsiderar o espaço para o novo, o inesperado e a criatividade dos sujeitos em agrupamentos (May, 2011). Para mais, ver Elias (1991), Bogner e Rosenthal (2009) e PfaffCzarnecka (2015).

2 Como Rosenthal et alii (2017), utilizamos os termos ilegalizados e ilegalização ao invés de "ilegal" ou "irregular" para reforçar a dimensão processual de práticas de exclusão social implementadas pelo Estado em relação aos migrantes, que ora avança na proteção destes, ora restringe suas liberdades e direitos. 
a baseada em eixos geográficos (migração Sul-Sul/Sul-Norte) e aquela que classifica momentos de mobilidade e imobilidade dos processos migratórios; b) a necessidade de reconstrução dos deslocamentos em sua totalidade para explicar os cursos migratórios, isso é, a limitação de abordagens que tomam o estado-nação como unidade básica de análise ao privilegiar movimentos que atravessam fronteiras nacionais; c) a tradução dos pertencimentos étnico e religioso e de ativos pessoais e familiares em estratégias que impedem reduzir as motivações da migração somente a determinantes estruturais.

\section{Abordagens do movimento no estudo das migrações}

Em anos recentes, o estudo dos fenômenos migratórios explorou paradigmas linguístico, cultural, espacial e, mais recentemente, da mobilidade e imobilidade (Faist, 2013; Glick Schiller, Salazar, 2012). Faist (2013) sugere que a abordagem da mobilidade enfatiza as diversas formas de mobilidade espacial do fenômeno da migração em detrimento de outras, de modo que não explica a gênese dos mecanismos que produzem e sustentam desigualdades sociais. Nesse sentido, Glick Schiller e Salazar (2012) usam o termo "regimes de mobilidade" para explorar os privilégios de movimento de alguns grupos em relação a outros, bem como o estigma e a proibição da migração de outros. A abordagem biográfica do movimento, por sua vez, sugere que as desigualdades na distribuição de poder em figurações e nos discursos vivenciados pelos migrantes devem ser reconstruídas antes, durante e após os deslocamentos (Bogner, Rosenthal, 2017).

Nesse mesmo sentido, Drotbohm e Winters (2018) sugerem o uso de uma abordagem de trajetória para superar a divisão entre origem e destino, ainda bastante difundida na abordagem transnacional da migração e que encobre relações e experiências em múltiplas localidades que são parte da migração. Insistimos, no entanto, que a reconstrução não se restrinja à trajetória, mas que explique também questões anteriores e posteriores a ela. Por isso, consideramos imprescindível a explicação dos movimentos migratórios em seu conjunto, isso é, deslocamentos, dentro ou fora do estado-nação, devem ser compreendidos um em relação ao outro e não separadamente ${ }^{3}$. Glick Schiller e Salazar (2012) indicam que a difusão do nacionalismo metodológico no estudo das migrações resultou em uma relevância exacerbada dos processos de mobilidade que atravessam fronteiras nacionais. Daí a tendência da academia de desconsiderar os deslocamentos internos e suas similaridades com os deslocamentos

\footnotetext{
3 Por isso usamos preferencialmente o termo migração para nos referir aos deslocamentos dos migrantes. No mesmo sentido, optamos pelo termo região ao invés de país como forma de levar em consideração especificidades regionais e para não tomar o estado-nação como unidade básica de análise. Para mais, ver Knöbl (2006) e Rosenthal (2012).
} 
transnacionais e de "ignorar tanto as histórias presentes quanto passadas do movimento e das interconexões humanas" (Glick Schiller, Salazar, 2012, p. 3).

No que diz respeito ao contexto brasileiro, é essencial reconstruir a memória coletiva associada à migração e aos diversos grupos como forma de combater "o esquecimento do tratamento sofrido por muitos imigrantes da periferia europeia no passado, e o esquecimento do passado colonial e neocolonial dos países de imigração" no presente (Monsma, Truzzi, 2018, p. 70). Com esse intuito, Rosenthal (2016, p. 33, tradução nossa) indica a necessidade de "demonstrar empiricamente quais agrupamentos reforçam quais versões da história coletiva em que figurações históricas e sociais com outros agrupamentos, sob quais condições históricas e com a ajuda de quais regras". Com isso, a mobilidade dos indivíduos é compreendida em relação ao seu contexto mais amplo do pertencimento individual a coletividades e às dinâmicas de poder entre agrupamentos sobre territórios.

Truzzi (2008, p. 214-215) indica que a noção de rede no estudo das migrações esclarece como oportunidades estruturais se traduzem em ações familiares e individuais e que os fenômenos migratórios estão atrelados a grupos de pessoas: indivíduos migram "como participantes de um processo social que se estend[e] muito além deles próprios". É em sentido semelhante que Seyferth (2005) defende que o uso de materiais biográficos nos estudos das migrações vai além de dinâmicas psicológicas individuais e informa também sobre fenômenos sociais vivenciados nas famílias e registrados em narrativas biográficas ${ }^{4}$. Por sua vez, Lems (2014) sugere que o foco dos estudos das migrações nas experiências das pessoas e em seus mundos da vida permite compreender particularidades e o cotidiano do "ser-no-lugar" (being-in-place) das pessoas que migram. Com isso, a contextualização das experiências daqueles que se deslocam permite compreender como conceitos legais e políticos abstratos são traduzidos em termos culturais no cotidiano dos sujeitos (Khosravi, 2018).

Tarrius (2000) sugere que o cotidiano se desenrola em lugares materiais ou não - que configuram dinâmicas de mobilidade atravessadas por arranjos relacionais de redes de solidariedade étnica e religiosa e pelo uso de ativos pessoais e familiares, configurados em "territórios de circulação". Grande parte da literatura sobre migração tende a cristalizar os processos em termos de "fluxos" de um ponto para outro e em uma alusão, emprestada das ciências naturais, que enfatiza um aspecto negativo de descontrole e exagero. No entanto, Tarrius (2000) apresenta a noção de que o movimento dos indivíduos ordena ativamente os espaços para desenvolver e ampliar a

4 Sobre a relação dos diversos níveis de análise e da dimensão social das biografias, ver Radenbach e Rosenthal (2012). 
agência, constituindo territórios de circulação. São ativos construídos pelas pessoas que se traduzem em vantagens em relação àqueles que ficaram em outro lugar. São deslocamentos que criam alternativas a fronteiras legais e que vão contra a noção de que migrantes se orientam passivamente por ganhos econômicos predeterminados por uma estrutura que reforça desigualdades e descontroles. Nesses territórios circulam, além de mercadorias e remessas financeiras, outros inúmeros ativos - ideias, informações, decisões, crenças, novas estratégias (Tarrius, 2000)5.

\section{A abordagem biográfica como perspectiva de análise do movimento}

$\mathrm{Na}$ consecução da proposta teórica apresentada, utilizamos uma compreensão de biografia enquanto construto social onde deslocamentos, discursos e inequidades de poder das figurações atreladas à mobilidade são registrados. A biografia dá acesso, nesse sentido, aos discursos e figurações tanto em uma perspectiva sincrônica quando diacrônica, permitindo uma reconstrução das vivências passadas e presentes dos sujeitos (Bogner, Rosenthal, 2017). Nossa investigação se deu a partir de um paradigma de pesquisa social interpretativa (Hoffmann-Riem, 1980) e foi fundamentada na sociologia do conhecimento (Berger, Luckmann, 1991), na sociologia de orientação fenomenológica (Schütz, 1963) e na sociologia dos processos e figurações (Elias, 1991). Os métodos utilizados para geração e análise de dados foram o de entrevista narrativa biográfica (Schütze, 2008; Rosenthal, 2014), reconstrução de caso biográfico (Rosenthal, 2014) e observação participante (Spradley, 1980), e implementamos uma lógica circular do processo de geração e análise de dados (Glaser, Strauss, 1967) ${ }^{6}$.

As entrevistas narrativas biográficas aconteceram entre 2016 e 2018 com indivíduos que recorreram ao auxílio do Centro de Atendimento ao Migrante (CAM) na cidade de Caxias do Sul, Rio Grande do Sul, Brasil. Além de entrevistas narrativas biográficas, utilizamos material etnográfico gerado na região desde 2013 para a análise dos casos. A participação no cotidiano das atividades do Centro resultou numa posição privilegiada de contato e diálogo com os migrantes. O Centro é uma entidade da sociedade civil que atua regionalmente no atendimento a migrantes, solicitantes de refúgio e refugiados. Entre janeiro de 2012 e junho de 2018, o CAM registrou 5.250 atendimentos a migrantes internacionais, sendo $67 \%$ dos atendidos oriundos

\footnotetext{
5 É importante enfatizar que os conceitos sugeridos foram utilizados nos termos de um conceito de sensibilização (sensitizing concept), como proposto por Herbert Blumer (1954).

6 Para mais detalhes sobre os passos de análise e o uso dos métodos de entrevista narrativa biográfica e de reconstrução de caso biográfico no estudo das migrações, ver Gonçalves e Cé Sangalli (2018); Cé Sangalli e Rinaldi (2018).
} 
de países africanos. A maioria dos migrantes atendidos pela entidade veio do Senegal (85\%) e de Gana (12\%).

Os dois casos reconstruídos foram escolhidos dentro de uma amostra de cerca de 20 entrevistas narrativas biográficas porque guardam semelhanças importantes, como idade, residência no sul do Brasil, condição de regularidade no país (inicialmente, ambos solicitaram refúgio, mas tiveram seus pedidos negados, acedendo ao direito de permanência com base em resolução do Conselho Nacional de Imigração), domínio do idioma português e pertencimento religioso ao islã. Ao mesmo tempo, os casos indicam a diversidade dos fenômenos migratórios para o Brasil e revelam como as vivências em diversas figurações nos países de origem incidem sobre as decisões vinculadas à mobilidade. Por exemplo, o pertencimento étnico torna-se relevante se tomada a perspectiva dos migrantes e da construção dos espaços em suas regiões de origem. Embora ambos fossem categorizados com base na cor de sua pele na esteira de um processo de racialização brasileiro nas cidades em que viviam à época das entrevistas, eles indicaram seu pertencimento de acordo com outros referenciais, marcados por relações e dinâmicas de poder de suas regiões de origem. Entretanto, pesa sobre ambos o marcador social "negro no Brasil" ou "imigrante africano", que demarca relações nas quais o "imigrante europeu" e seus descentes estão em condição mais estabelecida nesses locais. O recurso à não-diferenciação é explicitado na tendência homogeneizante de agrupamentos estabelecidos a se referirem aos biografados como "haitianos", contribuindo para o apagamento de seus pertencimentos e de sua história nessa figuração. A seguir, apresentamos a reconstrução dos casos de Hamid e Mahmud também como forma de registrar essas vivências e torná-las públicas ${ }^{7}$.

\section{Hamid: a rua, a rede religiosa e a reunião familiar}

Hamid nasceu na região de Louga, Senegal, em 1985. Ele é o terceiro filho dentre quatro, em uma família de etnia serer e, provavelmente, muçulmana, cujas gerações anteriores viveram na região. Louga fica na Bacia do Amendoim, um espaço cuja ocupação está associada principalmente às etnias wolof e serer (Lericollais, 1980). Embora tenha sido identificado por membros da comunidade de migrantes da região como serer, Hamid declarou-se wolof na situação da entrevista, um grupo majoritário e historicamente mais estabelecido que os serer nessa região. Aqueles passaram por um processo de islamização anterior a estes, que foram um dos últimos grupos a adotar o islã (Evans, 2016). Daí o fato de confrarias islâmicas, como a mouridia, serem associadas aos wolof, a despeito de muitos serer serem muçulmanos (Riccio,

Dados que pudessem identificar nossos parceiros de entrevista foram alterados. 
2005) ${ }^{8}$. Os serer também impuseram maior resistência à colonização francesa, o que os alijou, em diversos momentos, de cargos de poder distribuídos pelos franceses (Riccio, 2005). Histórias de escravização, rígida hierarquia social e, em menor grau, castas, ainda estão presentes na memória coletiva desses grupos e implicam em distinções marcantes ainda no presente, indicando a diversidade interna dos agrupamentos (Riccio, 2005).

A reconstrução das relações entre serer e wolof na figuração de origem revela dinâmicas de poder importantes para compreender a relação entre o interesse de apresentação de Hamid como wolof e seu pertencimento religioso. Com cerca de três anos de idade, ele perdeu sua mãe e foi deixado enquanto talibé (estudante-discípulo) em uma dahira (escola corânica) aos cuidados de um marabout (liderança religiosa que atua como instrutor e cuidador). A maior parte do relato de Hamid centrou-se em seu pertencimento religioso e na história do fundador da mouridia, cuja vida está associada a momentos de exílio e migração. Estes foram apresentados por Hamid entremeados a suas vivências, como os períodos que refere como os mais difíceis: a perda de sua mãe e a mendicância religiosa durante sua infância. O fenômeno talibé e sua relação com a mendicância infantil ainda são práticas usuais em algumas escolas corânicas no Senegal e geram controvérsia, dadas as denúncias de situações análogas à escravização e de violação de direitos fundamentais (Human Rights Watch, 2019; Zoumanigui, 2016).

Hamid frequentou brevemente uma "escola francesa", mas foi socializado principalmente como talibé sob tutela de seu marabout, o que esclarece um dos motivos de sua saída do Senegal. Sua relação de proximidade com seu marabout deu respaldo financeiro e religioso para suas iniciativas. Uma delas foi seu trabalho como comerciante em diversas regiões do Senegal, período em que se casou com Nogaye, sua prima. Foi também um momento de dificuldades financeiras, que levou o casal a planejar uma separação temporária para migrar. A estratégia adotada pelo casal parece ter sido a de diversificar as possibilidades inicialmente para, posteriormente, decidirem o local mais vantajoso para se reunirem. Nogaye mobilizou a residência permanente de seu pai na Espanha para reunir-se com ele no país, que já indicava uma série de dificuldades para o estabelecimento de migrantes do Senegal, especialmente para mulheres (Vives, Silva, 2017; Minder, 2018).

Hamid, por sua vez, buscou o apoio de seu marabout, que conseguiu visto e passagem aérea para o Brasil em 2012. O intermédio do marabout e da rede religiosa é difundido no Senegal para conseguir vistos, financiar passagens, acomodação, dentre outras necessidades para o deslocamento. Riccio (2005) sugere que a rede mouride é antes uma rede de mobilizações

8 A Mouridia é uma confraria islâmica sufista fundada pelo senegalês Cheikh Ahmadou Bamba (1853-1927). 
(networking) utilizada pelos agentes para diversas finalidades do que uma rede (network) em si. O marabout exerce sua influência sobre adeptos que estão em outra região usando redes sociais, visitando comunidades, organizando associações religiosas transnacionais, e coordenando a circulação de pessoas por esses espaços. A visita de um marabout confere prestígio à comunidade nucleada na dahira e reforça vínculos internos. O acesso à solidariedade do grupo está relacionado à participação em reuniões, à contribuição com recursos e à presença quando da visita de marabouts. É nesse espaço que os mourides atualizam seu compromisso de observação de uma ética religiosa compartilhada. A relação com o marabout não se limita a um pacto formal, mas tem implicações práticas na vida cotidiana, como na construção de possibilidades de circulação (Guijarro, 2012).

No Brasil, Hamid trabalhou por um período na indústria metalúrgica, ao mesmo tempo em que participou de atividades religiosas com a comunidade de migrantes do Senegal. Em 2013, após Hamid conseguir o direito de permanência no Brasil, ele e Nogaye utilizaram o dispositivo de reunião familiar para a mudança da esposa ao país. No final do mesmo ano, tiveram a primeira filha. Nogaye teve complicações durante a gestação e a filha nasceu prematura, resultando em outro período desgastante para o casal, uma vez que não tinham familiares para ajudá-los no Brasil. Depois de mudar de emprego algumas vezes, Hamid, com o apoio de Nogaye, iniciou a venda ambulante de refeições típicas do Senegal.

A socialização primária é essencial à construção de mundo dos sujeitos, o que influencia suas interpretações e seus cursos de ação (Berger, Luckmann, 1991). O processo de institucionalização no interior da confraria islâmica como talibé no contexto de uma cidade rural do Senegal na década de 80 configurou em Hamid uma relação específica com aquele território, incluindo aí a mendicância religiosa e suas vivências da rua. Os efeitos dessa socialização não são necessariamente negativos. O estreitamento dos laços de Hamid com seu marabout também trouxe vantagens. Embora o processo de institucionalização de Hamid não tenha sido o único fator determinante de seus cursos migratórios, seu engajamento institucional evidencia suas estratégias de uso de seu pertencimento religioso para implementar planos individuais, familiares e de seu grupo religioso.

No início de 2016, Nogaye retornou ao Senegal com a filha, então com três anos. Após cerca de quatro meses na Espanha para organizar a documentação da filha, ambas migraram para a Inglaterra. Quando um problema de saúde acometeu a filha, elas retornaram por um período breve à Espanha, onde Nogaye já conhecia o funcionamento do sistema de saúde. A mobilidade de Nogaye é marcada pela relação familiar e pelas redes dela decorrentes: a relação com o pai, o casamento com Hamid, a maternidade. Ao contrário do que ocorre 
com muitas esposas de senegaleses emigrados, as quais permanecem no Senegal com os filhos e dependem, muitas vezes, de remessas financeiras dos maridos, Nogaye rompeu com o papel tradicionalmente delegado às mulheres nessa figuração ao migrar sozinha - em um primeiro momento, para um país diferente daquele do marido e, posteriormente, com sua filha. Isso foi possível devido à mobilização das redes de parentesco e/ou religiosas sustentadas pelo casal durante a permanência no Brasil, que favoreceram a mobilidade entre Brasil, Senegal, Espanha e Inglaterra. São esses espaços que ensejam os planos futuros de Hamid de conseguir a naturalização como brasileiro, o que pode facilitar seu procedimento de reunião familiar na Europa, onde planeja trabalhar com o comércio de mercadorias entre Europa e Brasil.

Retornos e reencontros fazem parte do projeto migratório de reestabelecer-se, provisória ou definitivamente, na comunidade da qual se partiu. Segundo Hamid, esse movimento de idas e vindas ao Senegal é uma característica do senegalês: "sempre senegalês trabalha, trabalha e volta". O retorno como possibilidade gravita no horizonte de todo o migrante (Sayad, 2000), mas é precondição para a execução do projeto migratório para muitos migrantes do Senegal. Os retornos surgem como gratificação pelo "exílio", permitem reencontrar a família, abraçar um filho que nasceu quando se estava longe, chorar pelos familiares falecidos no período de ausência, distribuir presentes, proporcionar comida farta à família e amigos, celebrar festas religiosas, visitar seu marabout, peregrinar a locais sagrados para agradecer e pedir proteção. São, em grande medida, uma forma de compensação pelas dificuldades enfrentadas nos deslocamentos e o reconhecimento dessas vivências por parte daqueles que ficaram.

A reconstrução do caso de Hamid e, indiretamente, dos deslocamentos de Nogaye, expõe as limitações do uso de categorias restritivas como migração "Sul-Sul" e "Sul-Norte". As dinâmicas familiares, religiosas, de trabalho e retorno na trajetória de Hamid e sua família estão amalgamadas, constituindo espaços de circulação entre América do Sul, África Ocidental e Europa, subvertendo a lógica que procura entender esses deslocamentos exclusivamente baseada em categorias de "fluxos" entre eixos geograficamente circunscritos. Os dados empíricos demonstram que a construção desses espaços por membros da mesma família, dispersos em regiões distintas do globo, é concomitante. As dinâmicas dentro da constelação familiar, como casamentos, nascimentos e óbitos, estão atreladas não só à circulação de indivíduos, mas à construção dos espaços por onde as pessoas circulam. Além de os migrantes se orientarem pelas constelações familiares, suas estratégias são rearticuladas de acordo com mudanças jurídicas no nível do estado-nação e baseadas em ganhos ou desvantagens de taxas de câmbio atreladas às políticas monetárias de bancos centrais. Ao mesmo tempo em 
que respondem a determinações estruturais de regimes fundamentados na lógica do estado-nação, Nogaye e Hamid também derivam vantagens dessa lógica, como os dispositivos legais de reunião familiar e de acesso ao sistema público de saúde, sem deixar de se orientar pela lógica transnacional da rede sustentada pelo pertencimento religioso.

\section{Mahmud: marginalização, orfandade e deslocamento constante desde a infância}

Mahmud nasceu em 1987 em Acra, na região sul de Gana. Ele é o sexto filho dentre oito, e sua mãe é, provavelmente, a terceira esposa, dentre quatro, de seu pai. Os avós maternos e paternos de Mahmud viveram em Acra, são da etnia hauçá e parte de sua família é vinculada à confraria islâmica Tidiania ${ }^{9}$. As principais línguas faladas em Acra são inglês (herança da colonização britânica), akan (maior grupo linguístico em Acra e tido como grupo autóctone da região), hauçá e ga (Dakubu, 2009) ${ }^{10}$. O hauçá é a língua franca em espaços em Acra associados a comunidades de migrantes e seus descendentes, os quais vieram de outras regiões desde muitos séculos e por diversos motivos, principalmente comércio, islamização e a parceria com os britânicos nas forças armadas e em cargos do governo colonial (Casentini, 2018). Como muitos hauçás, a família paterna de Mahmud veio para Gana desde a Nigéria, localizada ao norte do país. Isso é um indício da mudança de posicionamento na figuração familiar, já que no norte de Gana há uma presença maior de hauçás muçulmanos do que no sul, predominantemente cristão (Pellow, 2001; Pellow, 2002).

Por muito tempo, os hauçás foram vistos por outros agrupamentos como grupo privilegiado pelos colonizadores britânicos em detrimento daqueles que viviam há mais tempo na região (Kobo, 2010). As disputas contribuíram para a marginalização de muitos hauçás, o que culminou em políticas de deportação de grupos ditos "alienígenas" ou "estrangeiros" após a independência (1957) até o final do século XX (Kobo, 2010). A história dos hauçás na região é um indicativo da vulnerabilidade das gerações anteriores da família de Mahmud frente às variações dos grupos no poder. A denominação dos hauçás como "nortistas" (northerners) reforça sua pertença geográfica e foi amplamente usada em campanhas políticas até recentemente (Kobo, 2010; Pellow, 1985). Dadas essas condições de marginalização, muitos hauçás formaram zongos, comunidades relacionadas à história do comércio e do islã na África Ocidental (Williamson, 2014). Muitos desses hauçás eram muçulmanos, o que contribuiu para a associação dos zongos a enclaves muçulmanos multiétnicos

Tidiania é uma tariqa (confraria) islâmica sufista de vertente sunita relacionada ao seu fundador, Ahmad al-Tijani (1737-1815), que nasceu na Argélia e morreu em Fes, Marrocos.

${ }^{10}$ Sobre a importância da língua materna na determinação do pertencimento, ver Bogner e Rosenthal (2009). 
que utilizam como língua franca o hauçá em regiões majoritariamente cristãs, como Acra (Pellow, 1985).

Em termos étnicos e religiosos, Mahmud e sua família são parte de uma comunidade com um longo passado de deslocamentos pela região, o que pode explicar o grande número de esposas de seu pai, indicativo de prosperidade econômica nesse contexto. Ao mesmo tempo, a posição de Mahmud na constelação familiar mais ampla representa dificuldades econômicas, uma vez que sua mãe não está na posição de primeira esposa nem ele na de primogênito, indicadores de acesso privilegiado à herança de bens e terras. Sua situação de nascimento enquanto hauçá na região de Acra evidencia o caráter de outsider em um contexto onde historicamente foram vistos como "invasores". Seu pertencimento religioso tidiane contribui para reforçar o caráter de marginalidade em um contexto majoritariamente cristão, somando-se à posição marginal de Mahmud e de sua mãe na constelação da família mais ampla.

Logo após o nascimento de Mahmud, e provavelmente enquanto sua mãe ainda estava grávida, seus pais se divorciaram. Apesar do aumento do número de casos de divórcio em diversas regiões da África Ocidental, as mulheres ainda sofrem maior estigma em regiões marcadamente religiosas (Searcey, 2019). Alegadamente, sua mãe era dependente alcoólica, o que levou ao divórcio de seus pais. Mahmud ficou sob o cuidado de sua mãe e avó materna devido ao grande número de filhos de seu pai. Cresceu, portanto, em um contexto onde conviveu com o estigma de ser filho de pais divorciados e de uma mãe dependente alcoólica, o que é de especial significado no contexto religioso de sua infância. Ao mesmo tempo, foi afastado do convívio com a família paterna, o que estava atrelado, nessa situação, ao sustento econômico e a condições mais privilegiadas de moradia.

Após o divórcio de seus pais, a situação econômica da família se deteriorou, contribuindo para que Mahmud mudasse de casa diversas vezes, além de não conseguir terminar sua educação formal em uma escola de língua inglesa. No entanto, passou aos cuidados do irmão da mãe, que tinha uma escola corânica, onde sofreu estigma devido sua situação familiar e econômica. Os castigos severos de seu tio contribuíram para que Mahmud evitasse frequentar a escola, ao passo que sua avó, ciente dos abusos e como medida protetiva, permitia que ele não fosse às aulas. Durante esse período, Mahmud também trabalhou com sua mãe na rua vendendo comida e, posteriormente, em uma farmácia. O chefe da farmácia, cuja família tinha histórico de migração para os Estados Unidos, contribuiu para pagar os estudos de Mahmud. Nesse período, recebeu ajuda de diversas pessoas com histórico de migração para concluir seus estudos, o que não aconteceu devido, dentre outros fatores, à instabilidade dos auxílios. 
Aos 13 anos de idade, Mahmud perdeu sua mãe em razão de complicações decorrentes da dependência alcoólica. A morte da mãe e, em seguida, da avó, contribuíram para a deterioração das condições de moradia de Mahmud. Ele e seu irmão mais novo passaram, então, a morar em propriedades da família materna, das quais não tinham a posse. Esse foi um período de instabilidade e insegurança, o que pode ser um indício do reforço de um processo de traumatização sequencial (Becker, 1999) relacionado ao divórcio de seus pais, à dependência alcoólica da mãe e à precariedade habitacional.

Sua relação com seus familiares se deteriorou mais em 2003, quando Mahmud, com cerca de 16 anos, engravidou sua prima, com quem teve uma filha. A prática de casar entre familiares próximos é comum nesse contexto principalmente para manter propriedades dentro da família. No entanto, Mahmud e sua prima não eram casados, e um filho fora do casamento em um contexto religioso pode não ser facilmente aceito. Isso contribuiu para o reforço da posição marginal de Mahmud em sua família. Nesse período, ele teve contato mais intenso com um time de futebol, situação relacionada não só ao pertencimento a uma coletividade frente às dificuldades impostas por sua família, mas também à possibilidade de sair do país e aos riscos do tráfico internacional de pessoas (Esson, 2015) ${ }^{11}$. No time de futebol, Mahmud teve o reconhecimento e o suporte que não recebera de sua família. Foi incentivado pelos companheiros do time a retomar seus estudos e percebeu a oportunidade de seguir carreira de jogador de futebol quando foi convidado para um time da primeira divisão. Concomitantemente, atuou no national support group ${ }^{12}$ da seleção nacional de Gana, o que permitiu que viajasse pelo continente africano em uma perspectiva que reforça seu pertencimento nacional. Foi nesse contexto que obteve seu passaporte para acompanhar a seleção nacional, o que estava próximo de seus planos de jogar futebol no exterior. Devido à baixa remuneração como jogador, continuou participando como percussionista na torcida organizada, com a qual foi para a Copa do Mundo na África do Sul (2010). No contexto de deslocamentos dentro do continente africano, sofreu um grave acidente quando se deslocava para um jogo em outubro de 2010. Após um período longo de recuperação, deixou de jogar futebol por conta das sequelas, mas usou sua participação na torcida organizada como forma de dar continuidade ao plano de sair de Gana e como principal meio de subsistência.

$\overline{11}$ Esson (2015) indica a percepção do futebol por muitos jovens de Gana como uma solução para incertezas socioeconômicas da capital. Segundo o autor, os jovens relacionam a carreira de jogador de futebol (ou em torcidas organizadas) a possibilidades de mobilidade espacial, um catalisador de mobilidade social. Para mais, ver Darby (2010).

12 Os National Supporters groups eram torcidas organizadas que, até 2018, recebiam apoio financeiro do governo para acompanhar times de futebol em viagens. 
No contexto de membro da torcida organizada da seleção nacional, foi incentivado a vir ao Brasil para a Copa do Mundo em 2014. No entanto, viajou sozinho já com a intenção de trabalhar no país. Inicialmente, foi recebido por um primo em Criciúma, Santa Catarina, região onde há uma comunidade significativa de ganeses, muitos muçulmanos. Antes de expirar o prazo regular de permanência de seu visto para a Copa, Mahmud solicitou refúgio e, posteriormente, teve seu pedido de permanência acolhido pelo Conselho Nacional de Imigração com base na análise de casos omissos à lei. No sul do Brasil, trabalhou brevemente em um frigorífico, como muitos outros migrantes da África Ocidental e do Haiti que chegaram na mesma época (Cavalcanti et alii, 2017), e em uma empresa de transportes. Nesse período, também retomou suas atividades de percussionista quando foi convidado para participar de um grupo artístico formado por migrantes do Senegal ${ }^{13}$. Em Passo Fundo, foi acolhido por uma instituição de apoio a migrantes vinculada à igreja católica. Ali, Mahmud participou da comunidade religiosa muçulmana local, especialmente da Tidiane, constituída por migrantes de origem nacional diversa.

O caso de Mahmud demonstra que a possibilidade de migrar integra uma estratégia já sedimentada nas práticas familiares, o que é evidenciado pelo contato precoce com familiares e conhecidos que viviam no exterior. Sua mãe e seu tio materno viajavam para a Nigéria como comerciantes. Experiências malsucedidas de migração também fazem parte do estoque de conhecimento de Mahmud. Em 2017, ele pediu demissão no Brasil e retornou para Gana por três meses para visitar familiares. No aeroporto de Acra, acompanhou a chegada de um grupo de migrantes de Gana deportados dos Estados Unidos. Nesse período, esteve com seu pai para celebrar o Eid al-Fitr, comemoração muçulmana que celebra o fim do período do Ramadã. Em seu retorno para Acra, Mahmud estava em uma posição mais estabelecida na constelação familiar, o que foi explicitado quando comprou uma vaca para dar de presente para seu pai. O retorno temporário também indica a mudança do seu posicionamento em relação à família, uma vez que ele tem o conhecimento e os recursos necessários para circular entre diversas regiões. Essa posição privilegiada é negociada com pessoas da comunidade e familiares: ele compartilhou seu contato no Brasil apenas com os mais próximos devido às demandas de auxílio relacionadas às expectativas e fantasias da família mais ampla advindas da percepção de Mahmud como migrante "bem-sucedido" e adulto respeitável (Langevang, 2008).

\footnotetext{
${ }^{13}$ Sobre a importância da música na construção do pertencimento em migrantes no sul do Brasil, ver Cé Sangalli (2018).
} 
Durante o período que esteve em Gana em 2017, Mahmud também tentou conseguir um visto de turista para a França, pois acreditava que sua estadia no Brasil atuaria a seu favor. As justificativas para mudar para a Europa estavam orientadas também por vantagens financeiras: "o Brasil é bom. Eu gosto muito daqui, mas eu preciso ganhar dinheiro para montar um negócio pra mim". Essas experiências evidenciam os potenciais de mobilidade social atrelados àqueles que saem do país (Prothmann, 2017), bem como o planejamento constante de novos deslocamentos para regiões onde a taxa de conversão da moeda representa ganhos maiores. No caso de Mahmud, suas opções por países na Europa ou para Estados Unidos, Austrália e Japão indicam o conhecimento dos ganhos advindos de remessas financeiras a partir dessas regiões e os constrangimentos econômicos para a permanência no Brasil, como a dificuldade de guardar algum dinheiro após pagar seus custos mensais básicos, como moradia e alimentação. O conhecimento sobre possibilidades migratórias é vasto no caso de Mahmud e a experiência de migração e os processos de mobilidade de seus familiares e conhecidos são integrados a suas vivências, como o relato sobre um conhecido que vivia no Brasil e faleceu após chegar nos Estados Unidos depois de um percurso arriscado pela América Central, justificativa que ele utiliza para não seguir o mesmo caminho ${ }^{14}$.

A situação de vida às margens e sua relação com a mobilidade de jovens ganeses já foi indicada em outros estudos (Langevang, Gough, 2009), bem como os ganhos socioeconômicos relacionados a esses deslocamentos (Nieswand, 2013). Os ganhos em termos de remessas financeiras a partir do Brasil, no entanto, parecem ser relativamente menores se comparados a outras regiões, como Estados Unidos e Europa. No entanto, a relativa facilidade para entrar e permanecer no país no contexto da Copa do Mundo em 2014 contribuiu para a integração do Brasil nesses percursos, indicando a necessidade de levar em consideração movimentações anteriores e posteriores à trajetória para o país de forma a não subsumir a totalidade e a diversidade dos fenômenos migratórios a categorias como "migrações Sul-Sul" ou "Sul-Norte". Esse reducionismo encobre dinâmicas que só são apreendidas quando reconstruímos não apenas os processos de deslocamento, mas também as figurações vivenciadas pelos indivíduos antes, durante e após o curso migratório. O caso de Mahmud evidencia deslocamentos recorrentes desde a infância, assim como a vulnerabilidade permanente em termos de moradia e um posicionamento outsider em diversas figurações. Daí que suas possibilidades atuais de participação no Brasil estejam associadas a uma multiplicidade de fatores e não a apenas uma questão, como o trabalho ou a situação socioeconômica precária no país de origem, comumente indicados como causas para a migração pela literatura especializada. Suas condições de trabalho não garantem excedentes

${ }^{14}$ Sobre o percurso entre Brasil e América do Norte, ver Drotbohm e Winters (2018). 
financeiros suficientes para remeter àqueles que estão em Gana, caso fosse sua vontade. Ao mesmo tempo, o Brasil configura-se como mais um, dentre outros, espaço em um campo diverso de possibilidades, como viver longe das responsabilidades familiares e dos constrangimentos religiosos, por exemplo, ou vivenciar uma situação de marginalidade mais tolerável do que a anterior, a despeito das possíveis precariedades trabalhistas e da eventual ausência de garantias socioeconômicas.

\section{Considerações Finais}

Os casos reconstruídos são representativos da diversidade do fenômeno social das migrações na África, América Latina e Europa. Os dados empíricos evidenciam o caráter processual dos deslocamentos anteriores e posteriores à chegada no Brasil, bem como a agência individual em constituição mútua com os constrangimentos das figurações de poder em cada região e ao longo do tempo. Também demonstram como a construção dos sentimentos de pertencimento em diversos espaços está atrelada aos projetos de novos deslocamentos, à formação de redes em diferentes regiões e aos "momentos de espera" e estabelecimento. Essas novas dinâmicas e circularidades colocam desafios para a análise na medida em que não se enquadram totalmente em categorias consagradas no campo dos estudos das migrações, como as noções de expulsão/atração, emigração/imigração e migração/retorno. As dinâmicas e redes sustentadas nos cursos dos migrantes formam o "saber circular" dos territórios. Essa noção contribui para compreender os espaços de agência construídos por esses migrantes tanto nos cursos migratórios, tomados desde sua região de origem, como nos espaços compartilhados com outros agrupamentos em outras figurações ao longo desse curso, expressos por afetividades, pertencimentos, afinidades e interesses comuns, e que configuram possibilidades e novos cursos de circulação.

As dinâmicas familiares (tipos de relação, estrutura, pertencimento), compreendidas como um aspecto dos territórios circulatórios criados e habitados por migrantes da África Ocidental no Brasil, constroem, assim como podem limitar, movimentos. Os processos migratórios, para além da sua dimensão econômica, também estão constituídos em relação às dinâmicas familiares, isso é, pela situação ocupada na constelação familiar e pelo engajamento para manter ou não seu posicionamento em relação aos agrupamentos em distintas figurações. A migração atualiza e transforma vínculos, mesmo que os processos de mobilidade geográfica estejam, em boa parte, amparados em redes de parentesco, de amizade ou religiosas. Ao mesmo tempo, as prerrogativas legais do direito à reunião familiar também passam a integrar os estoques de conhecimento dos migrantes e suas dinâmicas de mobilidade, estendidas a conhecidos e familiares. 
Por fim, observa-se nos cursos apresentados que o planejamento da migração para outra região não necessariamente prevê investimentos (subjetivos ou materiais) nos processos de participação local (aquisição de bens, aprender um idioma, participar em espaços sociais como associações de moradores, casamentos, dentre outros), tão caros aos discursos da sociedade civil e dos estados no que tange às discussões sobre políticas migratórias. Os territórios circulatórios construídos e vivenciados pelos migrantes da África Ocidental no Brasil têm-se consagrado à margem dos discursos sociais dos grupos estabelecidos, que tendem a imaginar esses agrupamentos como coletivos estáticos e passivos de intervenção, desconsiderando sua autonomia e as vantagens sociais que eles vêm construindo à medida que geram novas circularidades a partir das vivências no Brasil.

A circulação do indivíduo por diversas figurações estabelece e sustenta um espaço propício ao movimento. Os deslocamentos são constantes e a construção dos pertencimentos é intermitente, o que põe em questão uma diferenciação entre mobilidade e imobilidade. As mobilizações dos estoques de conhecimento construídos nos cursos de migração são recorrentes e concomitantes ao deslocamento geográfico. Ao mesmo tempo que os regimes de mobilidade implementam discrepâncias de poder contra e a favor de certos grupos, as estratégias dos grupos marginalizados se transformam e traduzem a marginalização e a ilegalização colocadas pelas figurações em ganhos relativos para dar continuidade aos movimentos. As sociedades "de destino", no afã de cristalizar transformações constantes para "solucionar" aquilo que os discursos determinam como um problema, utilizam lógicas da permanência, que ora se esforça para estancar movimentos, ora para "integrar" quem se desloca. Nesse sentido, subvertem a perspectiva de um fenômeno que transborda a estaticidade de categorias geográficas e normativas. Mesmo na (des)integração social, o migrante participa. Mesmo ilegalizados, os circuitos existem e instauram a lógica da diversidade de um movimento constante.

\section{Referências bibliográficas}

BECKER, David. Trauerprozesse und Traumaverarbeitung im interkulturellen Zusammenhang. Zeitschrift für Politische Psychologie, v. 7, n. 1+2, p. 165-182, 1999.

BERGER, Peter; LUCKMANN, Thomas. The social construction of reality. London: Penguin, 1991.

BLUMER, Herbert. What is wrong with social theory? American Sociological Review, v. 19, n. 1, p. 3-10, 1954.

BOGNER, Artur; ROSENTHAL, Gabriele. Introduction: Ethnicity, biography and options of belonging. In: ROSENTHAL, Gabriele; BOGNER, Artur (eds.). Ethnicity, Belonging and Biography. Berlin: LIT Verlag, 2009, p. 9-23. 
BOGNER, Artur; ROSENTHAL, Gabriele. Biographies - Discourses - Figurations: Methodological considerations from the perspectives of social constructivism and figurational sociology. In: ROSENTHAL, Gabriele; BOGNER, Artur (eds.). Biographies in the Global South. Frankfurt: Campus, 2017, p. 15-49.

BRUBAKER, Rogers. Ethnicity without groups. Cambridge: Harvard University Press, 2004.

CASENTINI, Giulia. Migration networks and narratives in Ghana: a case study from the Zongo. Africa, v. 88, n. 3, p. 452-468, 2018.

CAVALCANTI, Leonardo; OLIVEIRA, Antônio; ARAUJO, Dina; TONHATI, Tania. A inserção dos imigrantes no mercado de trabalho brasileiro. Relatório Anual 2017. Brasília: Observatório das Migrações Internacionais, 2017.

CÉ SANGALLI, Lucas. A construção social do espaço para si: pertencimento na biografia de um migrante. Mosaico, Rio de Janeiro, v. 9, n. 14, p. 338-358, 2018.

CÉ SANGALLI, Lucas; RINALDI, Débora. Pesquisa social interpretativa alemã: os métodos de entrevista narrativa biográfica e reconstrução biográfica de caso. Revista Em Tese, Florianópolis, v. 15, n. 2, p. 107-136, 2018.

DAKUBU, Kropp. The historical dynamic of multilingualism in Accra. In: MCLAUGHLIN, Fiona (ed.). The Languages of Urban Africa. London: Continuun, 2009, p. 19-31.

DARBY, Paul. 'Go Outside': The History, Economics and Geography of Ghanaian Football Labour Migration. African Historical Review, v. 42, n. 1, p. 19-41, 2010.

DROTBOHM, Heike; WINTERS, Nanneke. Transnational Lives en Route: African Trajectories of Displacement and Emplacement across Central America. In: Working Papers of the Department of Anthropology and African Studies of the Johannes Gutenberg University Mainz, 175, 2018.

ELIAS, Norbert. The society of individuals. Oxford: Basil Blackwell Ltd., 1991.

ELIAS, Norbert. Towards a theory of established-outsider relations. In: ELIAS, Norbert; SCOTSON, John. The established and the outsiders. Dublin: University College Dublin Press, 2008, p. 1-36.

ELIAS, Norbert. Figuration. In: KOPP, Johannes; STEINBACH, Anja (orgs.). Grundbegriffe der Soziologie (12. Auflage). Wiesbaden: Springer VS, 2018, p. 115-117.

ESSON, James. You have to try your luck: male Ghanaian youth and the uncertainty of football migration. Environment and Planning A, v. 47, n. 6, p. 1383-1397, 2015.

EVANS, Ruth. Gendered struggles over land: shifting inheritance practices among the Serer in rural Senegal. Gender, Place \& Culture, v. 23, n. 9, p. 1-16, 2016.

FAIST, Thomas. The mobility turn: a new paradigm for the social sciences? Ethnic and Racial Studies, v. 36, n. 11, p. 1637-1646, 2013.

GLASER, Barney; STRAUSS, Anselm. The discovery of grounded theory: strategies for qualitative research. New Brunswick: Aldine Transaction, 1967. 
GLICK SCHILLER, Nina; SALAZAR, Noel B. Regimes of Mobility Across the Globe. Journal of Ethnic and Migration Studies, v. 39, n. 2, p. 1-18, 2012.

GONÇALVES, Maria do Carmo dos Santos; CÉ SANGALLI, Lucas. A abordagem biográfica das migrações transnacionais: os casos haitiano e senegalês no Brasil. Revista Brasileira de Pesquisa (Auto)biográfica, v. 3, p. 91-108, 2018.

GUIJARRO, Ester Massó. La figura del marabout: ¿dominación o emancipación en la diáspora migratoria murid? Astrolabio: revista internacional de filosofia, n. 13, p. 287-295, 2012.

HUMAN RIGHTS WATCH. Senegal: Make Talibé Children a Campaign Focus. 2019. Disponível em: <https://www.hrw.org/news/2019/02/01/senegal-maketalibe-children-campaign-focus $>$. Acesso em: 02.04.2019.

HOFFMANN-RIEM, Christa. Die Sozialforschung einer interpretativen Soziologie. Der Datengewinn. Kölner Zeitschrift für Soziologie und Sozialpsychologie, v. 32, Jahrgang, n. 2, p. 339-372, 1980.

KNÖBL, Wolfgang. Of contingencies and breaks: the US-American South as an anomaly in the debate on multiple modernities. European Journal of Sociology, v. 47, n. 1, p. 126-167, 2006.

KHOSRAVI, Shahram. Afterword. Experiences and stories along the way. Geoforum, p. 1-4, 2018.

KOBO, Ousman. We are citizens too: The politics of citizenship in independent Ghana. The Journal of Modern African Studies, v. 48, p. 67-94, 2010.

LANGEVANG, Thilde. 'We are managing!' Uncertain paths to respectable adulthoods in Accra, Ghana. Geoforum, v. 39, p. 2039-2047, 2008.

LANGEVANG, Thilde; GOUGH, Katherine. Surviving through movement: the mobility of urban youth in Ghana. Social \& Cultural Geography, v. 10, n. 7, p. 741-756, 2009.

LEMS, Annika. Placing Displacement: Placemaking in a World of Movement. Ethnos: Journal of Anthropology, v. 81, n. 2, p. 1-23, 2014.

LERICOLLAIS, André. Le Basin de I'Arachide. In: PÉLISSIER, Paul (ed.). Atlas du Sénégal. Paris: Groupe J.A., 1980, p. 50-53.

MAY, Vanessa. Self, Belonging, and Social Change. Sociology, v. 45, n. 3, p. 363378, 2011.

MINDER, Raphael. Spain Took Them in as Migrants, but Scorns Them as Street Vendors. New York Times. 2018. Disponível em: <https://www.nytimes. com/2018/09/02/world/europe/spain-street-vendors-migrants.html>. Acesso em: 04.04.2019.

MONSMA, Karl; TRUZZI, Oswaldo. Amnésia social e representações de imigrantes: consequências do esquecimento histórico e colonial na Europa e na América. Sociologias, Porto Alegre, v. 20, n. 49, p. 70-108, 2018.

NIESWAND, Boris. The burgers' paradox: Migration and the transnationalization of social inequality in southern Ghana. Ethnography, v. 15, n. 4, p. 403-425, 2013. 
PELLOW, Deborah. Muslim Segmentation: Cohesion and Divisiveness in Accra. The Journal of Modern African Studies, v. 23, p. 419-444, 1985.

PELLOW, Deborah. Differences and Urban Spatial Forms: Elements of Boundedness in an Accra Community. American Anthropologist, v. 103, n. 1, p. 59-75, 2001.

PELLOW, Deborah. Migrant Communities in Accra, Ghana: Marginalizing the Margins. In: GRANT, Richard; SHORT, John (eds.). Globalization and the Margins. London: Palgrave Macmillan, 2002, p. 111-129.

PFAFF-CZARNECKA, Joanna. Multiple Belonging and the Challenges to Biographic Navigation. 2013. ISA e-Forum. Disponível em: <https://www.academia. edu/13494185/Multiple_Belonging_and_the_Challenges_to_Biographic Navigation?auto=download $>$. Acesso em: 29.09.2018.

PROTHMANN, Sebastian. Migration, masculinity and social class: Insights from Pikine, Senegal. International Migration, Hoboken, v. 54, n. 4, p. 96-108, 2017.

RADENBACH, Niklas; ROSENTHAL, Gabriele. Das Vergangene ist auch Gegenwart, das Gesellschaftliche ist auch individuell. Sozialer Sinn, v. 13, n. 1, p. 3-38, 2012.

RICCIO, Bruno. Talkin' about Migration - Some Ethnographic Notes on the Ambivalent Representation of Migrants in Contemporary Senegal. Vienna Journal of African Studies, v. 8, p. 99-118, 2005.

ROSENTHAL, Gabriele. A plea for a more interpretive, more empirical and more historical sociology. In: KALEKIN-FISHMAN, Devorah; DENIS, Ann (eds.). Tradition and renewal: the shape of Sociology for the 21st Century. London: SAGE, 2012, p. 202-217.

ROSENTHAL, Gabriele. História de vida vivenciada e história de vida narrada. Gestalt e estrutura de autoapresentações biográficas. Porto Alegre: Edipucrs, 2017.

ROSENTHAL, Gabriele. Pesquisa social interpretativa. Uma introdução. Porto Alegre: Edipucrs, 2014.

ROSENTHAL, Gabriele. The social construction of individual and collective memory. In: SEBALD, Gerd; WAGLE, Jatin (eds.). Theorizing Social Memories: Concepts, Temporality, Functions. London: Routledge, 2016, p. 2-55.

ROSENTHAL, Gabriele; BAHL, Eva; WORM, Arne. Illegalized migration courses from the perspective of biographical research and figurational sociology: The land border between Spain and Morocco. In: ROSENTHAL, Gabriele; BOGNER, Artur (eds.). Biographies in the Global South. Frankfurt: Campus, 2017, p. 103-159.

SAYAD, Abdelmalek. O retorno: elemento constitutivo da condição do imigrante. Travessia: revista do migrante, ano XIII, número especial, p. 7-32, 2000.

SEARCEY, Dionee. A Quiet Revolution: More Women Seek Divorces in Conservative West Africa. New York Times. 2019. Disponível em: < https://www. nytimes.com/2019/01/06/world/africa/niger-divorce-women.html>. Acesso em: 03.03.2019.

SEYFERTH, Giralda. Cartas e Narrativas Biográficas no Estudo da Imigração. In: DEMARTINI, Zeila; TRUZZI, Oswaldo (org.). Estudos migratórios: perspectivas metodológicas. São Carlos: EdUFSCar, 2005, p. 13-51. 
SPRADLEY, James. Participant observation. Fort Worth: Harcourt Brace Jovanovich College Publishers, 1980.

SCHÜTZ, Alfred. On phenomenology and social relations. Chicago: The University of Chicago Press, 1963.

SCHÜTZE, Fritz. Biography analysis on the empirical base of autobiographical narratives: how to analyze autobiographical interviews - Part One. 2008. Disponível em: <http://www.zsm.ovgu.de/zsm_media/Das+Zentrum/ Forschungsprojekte/INVITE/B2_1-p-140.pdf>. Acesso em: 26.12.2018.

TARRIUS, Alain. Leer, describir, interpretar las circulaciones migratorias: conveniencia de la noción de territorio circulatorio. Los nuevos hábitos de la identidad. Relaciones. Estudios de historia y sociedad, v. 21, n. 83, p. 38-66, 2000.

TRUZZI, Oswaldo. Redes em processos migratorios. Tempo Social, v. 20, n. 1, p. 199-218, 2008.

VIVES, Luna; SILVA, Iria. Senegalese migration to Spain: transnational mothering practices. Journal of Ethnic and Migration Studies, v. 43, n. 3, p. 495-512, 2017.

WILLIAMSON, Emily. Understanding the Zongo. Processes of socio-spatial marginalization in Ghana (Dissertação de Mestrado). Boston: Massachusetts Institute of Technology (MIT), Departamento de Arquitetura, 2014.

ZOUMANIGUI, Antoinette. On the Talibé Phenomenon: A Look into the Complex Nature of Forced Child Begging in Senegal. International Journal of Children's Rights, v. 24, p. 185-203, 2016. 